\title{
Effect of energy drink dose on exercise capacity, heart rate recovery and heart rate variability after high-intensity exercise
}

\author{
Sang Min An, Jong Suk Park and Sang Ho Kim* \\ School of Global Sport Studies, Korea University, Sejong, Korea
}

(Received: 2014/01/20, Revised: 2014/02/10, Published online: 2014/02/11)

[Purpose] The purpose of this research was to investigate the effects of exercise capacity, heart rate recovery and heart rate variability after high-intensity exercise on caffeine concentration of energy drink. [Methods] The volunteers for this study were 15 male university student. 15 subjects were taken basic physical examinations such as height, weight and BMI before the experiment. Primary tests were examined of $\mathrm{VO}_{2}$ max per weight of each subjects by graded exercise test using Bruce protocol. Each of five subject was divided 3 groups (CON, ECG I, ECG II) by matched method based on weight and $\mathrm{VO}_{2}$ max per weight what gained of primary test for minimize the differences of exercise capacity and ingestion of each groups. For the secondary tests, the groups of subjects were taken their materials before and after exercise as a blind test. After the ingestion, subjects were experimented on exercise test of $\mathrm{VO}_{2} \max 80 \%$ by treadmill until the all-out. Heart rate was measured by 1minute interval, and respiratory variables were analyzed VO2, VE, VT, RR and so on by automatic respiratory analyzer. And exercise exhaustion time was determined by stopwatch. Moreover, HRV was measured after exercise and recovery 3 min. [Results] Among the intake groups, ECG II was showed the longest of exercise exhaustion time more than CON group $(p=.05)$. Result of heart rate during exercise according to intake groups, there was significant differences of each time $(p<.001)$, however, not significant differences of each groups and group verse time $(\mathrm{p}>.05)$. Result of RPE during exercise according to intake groups, there was significant differences of each time $(\mathrm{p}<.001)$, however, not significant differences of each groups and group verse time $(\mathrm{p}>.05)$. [Conclusion] In conclusion, EDG II showed the significant increase of exercise exhaustion time more than CON group $(\mathrm{p}=.05)$ and not significant differences in HR, RPE, RER, HRV, HRR, blood pressure ( $\mathrm{p}>.05)$. Therefore, $2.5 \mathrm{mg} / \mathrm{kg}-1$ ingestion of energy drink might be positive effect to increase exercise performance capacity without side-effect in cardiovascular disease. [Keyword] Energy Drink, Caffeine, HRV, HRR, Exercise, Cardiovascular

\section{INTRODUCTION}

\section{Necessity and purpose of the study}

Among energy drinks available in Korean market, 'Hot Six,' an energy drink from Lotte Chilsung, marked 250 million won sales in Jan. 2011. Since 2012, its sales have recorded more than 3 billion won every month, indicating rapid growth of energy drink market in Korea. A sales analysis on the market showed that energy drinks are sought mostly by young people - those in their teens and 20s accounted for $23 \%$ and $41 \%$ of the consumers respectively. Energy drinks are known to boost mental and physical energy of those who drink them [1]. Caffeine, taurine and citric acid are considered primary ingredients that boost mental and physical energy in consu- mers [2]. The primary ergogenic ingredient in the drinks is known to be caffeine [3].

The caffeine level in energy drinks makes a whole lot of difference [4]. Caffeine is readily accessible in everyday life and consumed through various drinks and foods [5,6]. However, too much caffeine consumption can cause a range of side effects - anxiety, insomnia, accelerated heartbeat, caffeine addiction, caffeine withdrawal, etc. [7]. Considering these adverse effects, Korea's Ministry of Food \& Drug Safety made caffeine content warning label mandatory for all drinks except green tea and coffee. The label warns people that beverages containing more than $0.15 \mathrm{mg} / \mathrm{mL}$ level of caffeine are classified as a high caffeine drink and should be avoided by those sensitive to caffeine such as children and pregnant woman [8].

\footnotetext{
* Corresponding author: Sangho Kim, Tel. 82-44-860-1371, Fax. 82-44-860-1589, Email. ksh1905@korea.ac.kr

(c)2014 The Korean Society for Exercise Nutrition
} 
When caffeine is absorbed in the body, it stimulates sympathetic nervous system and results in a rise in plasma catecholamine that allows the body to adapt to the stress created by physical exercise. In the heart, it prompts secretion of norepinephrine and epinephrine to increase the rate and force of the muscle's contractions. They raise the rate and force of the heart, thereby increasing the blood pressure and make the heart beat faster [9]. Catecholamine production increases the availability of free fatty acids as muscle substrates during work, thus allowing glycogen sparing, improving physical performance [10,11]. Since Costill et al. [12] reported the improvement of physical performance after intake of caffeine, many studies have reported the same and claimed that ergogenic effect of caffeine was seen in people who had at least more than $2.5 \mathrm{mg} / \mathrm{kg}^{-1}$. dose of caffeine intake $[13,14]$. However, caffeine intake of more than $3 \mathrm{mg} / \mathrm{kg}^{-1}$ or 200 $\mathrm{mg} / \mathrm{kg}^{-1}$ resulted in side effects such as stomach pain, anxiety, hypersensitiveness, faster heartbeats, etc. [15]. As concerns grow bigger over increasing caffeine intake due to increasing consumption of energy drinks, studies that investigate the effects of caffeine intake on physical performance within the safe caffeine limit that would not cause side effects is needed. Also, dose of caffeine intake needs to be analyzed by physique of each person in order to ensure safety and establish systematic data. Thus, this study intends to analyze the effects of caffeine-containing energy drink consumption on physical performance during high intensity exercise and hear rate recovery (HRR) and heart rate variability (HRV). It also aims to Fig. out the dose of caffeine intake which may improve physical performance without triggering side effects.

\section{METHODS}

\section{Subjects}

15 male students at Department of Social Physical Education of K University became the subjects of this study. In order to make sure that participants' in each group are similar in their $\mathrm{VO}_{2}$ max, height, weight, etc., matching methods were used to group the 15 participants into three groups (5 per each group) - control group that drank water without caffeine (0 $\mathrm{mg} / \mathrm{kg}^{-1}$ caffeine), ECG (energy consumption group) I that drank energy drinks with $1.25 \mathrm{mg} / \mathrm{kg}^{-1}$ dose of caffeine and ECG (energy consumption group) $I I$ that drank energy drinks with $2.5 \mathrm{mg} / \mathrm{kg}^{-1}$. Physical characteristics of the participants is summarized in the $<$ Table $1>$.

\section{Measuring instruments and methods}

\section{Measurement of physiques}

Subjects were not allowed to eat or exercise for six hours before the test and they were told to urinate and defecate before the test. They wore shorts and short sleeve T-shirt when measuring their height using a height machine (Health mate 9600A, Sewoo, Seoul, Korea) and weight and body composition with body composition analyzer (Inbody 720, Biospace, Seoul, Korea).

\section{Exercise load method}

In order to serve the purpose of this study, two tests preliminary test and primary test -were conducted at one-week interval in a way to get rid of any possible influence. All subjects were told not to drink alcohol or caffeinated drink or food on the previous day. They fasted for six hours before the tests which were conducted at the same time of the day. Subjects arrived at the test room two hours before the test and had their body composition measured and sat on chairs until the test. Burce protocol was used to measure their $\mathrm{VO}_{2}$ max while they ran on treadmill (Cosmed T150, Rome, Italy) until they reach their maximum, Automatic metabolic gas analyzer (Tru One 2400, Parvo Medics, UT, USA) was used to measure gas during exercise. A 5-minute warm-up - starting from $1.7 \mathrm{mph}$ to gradually reach less than $70 \%$ of $\mathrm{VO}_{2}$ max - was conducted based on a study by Darren et al. [16] and then each subject ran at $80 \%$ of his/her $\mathrm{VO}_{2}$ max. Respiratory parameters, heart rate, and rating of perceived exertion (RPE) were checked every minute during the exercise. Gas analysis

Table 1. Physical characteristic of subjects

\begin{tabular}{|c|c|c|c|c|c|c|}
\hline Group & $\mathrm{n}$ & Age (yrs) & Height $(\mathrm{cm})$ & Weight (kg) & BMI $\left(\mathrm{kg} / \mathrm{m}^{2}\right)$ & $\mathrm{VO}_{2} \max (\mathrm{mL} / \mathrm{kg} / \mathrm{min})$ \\
\hline $\mathrm{CON}$ & 5 & $21.20 \pm 1.79$ & $177.60 \pm 6.54$ & $72.20 \pm 4.09$ & $23.20 \pm 1.64$ & $57.20 \pm 10.76$ \\
\hline ECG I & 5 & $21.40 \pm 1.14$ & $177.60 \pm 4.39$ & $73.20 \pm 5.22$ & $23.40 \pm 1.14$ & $59.20 \pm 5.63$ \\
\hline ECG II & 5 & $20.20 \pm 0.45$ & $175.20 \pm 5.27$ & $72.60 \pm 4.04$ & $23.40 \pm 0.89$ & $59.60 \pm 2.88$ \\
\hline $\mathrm{F}$ & & 1.319 & .312 & .063 & .042 & .159 \\
\hline $\mathrm{P}$ & & .303 & .738 & .939 & .959 & .855 \\
\hline
\end{tabular}

Values are Mean \pm Standard deviation

CON : control group, ECG I : energy drink $1.25 \mathrm{mg} / \mathrm{kg}^{-1}$ consumption group, ECG II: energy drink $2.5 \mathrm{mg} / \mathrm{kg}^{-1}$ consumption group 
data, heart rate, respiratory index, etc. displayed on the monitor were checked while subjects were exercising. They were told to stop exercise when they reached $90 \%$ of their maximum predicted heart rate (220-age) or exceeded a respiratory exchange ratio of 1.15 . Subjects were told to walk for 60 seconds at $1.2 \mathrm{mph}$ after stopped running and sat on chairs to monitor changes in their records. All tests were done in the same condition - room temperature of $22-25^{\circ}$, relative humidity $45 \pm 5 \%$.

\section{Ingredients of energy drinks and caffeine intake}

The Vaults of Erowid - an online library containing tens of thousands of pages of information about psychoactive drugs, plants, and chemicals - classified the caffeine intake into four: minimal intake $(10 \mathrm{~m}-20 \mathrm{mg})$, normal intake (50 - $100 \mathrm{mg}$ ), high intake (150 - $400 \mathrm{mg}$ ), and large intake (more than $400 \mathrm{mg}$ ). And a study by Reissig et al. [15], Graham et al. [17] said that caffeine intake of more than $3 \mathrm{mg} / \mathrm{kg}^{-1}$ or $200 \mathrm{mg} / \mathrm{kg}^{-1}$ resulted in side effects such as stomach pain, anxiety, hypersensitiveness, faster heartbeats, etc., Thus, we chose two caffeine doses between $3 \mathrm{mg} / \mathrm{kg}^{-1}$ and $200 \mathrm{mg} / \mathrm{kg}^{-1}$. Amount of ingredients in the two energy drinks (Hot6, Hot6 light) were made same except for caffeine (30 mg, $60 \mathrm{mg}$ respectively) in order to differentiate the caffeine intake by weight of each subject. In order to get the appropriate caffeine intake, we've used a formula - (weight $\times$ caffeine intake)/ caffeine concentration. For ECG I, $91.50 \pm 6.52 \mathrm{mg}$ of caffeine were used, while $181.5 \pm 10.09 \mathrm{mg}$ of caffeine were used for ECGII. Amount of normal intake and high intake were chosen within the range that would not trigger side effects (between $85.25 \mathrm{mg}$ and $192.43 \mathrm{mg}$ ). Caffeine was put into the drinks using beakers and droppers. The subjects drank the beverage 60 minutes before the tests.

\section{Measurement of heart rate}

Heart rate was measured by Telemeter Heart Checker (RS 100, Polar, Finland) before and during the exercise at 1 minute interval. The rate was also checked 1,2 , and 3 minutes after the exercise.

\section{Measurement of blood pressure}

Blood pressure was measured by a digital blood pressure monitor (model412 Quinton Co., USA) before and two minutes after the exercise in order to compare the effects of each dose of caffeine on blood pressure before and after the exercise.

\section{Measurement of $H R V$}

HRV (heart rate variability) was measured by SA3000P
(Medicore. Co., Seoul, Korea) for five minutes before and 60 minutes after drinking the energy drinks and also after the exercise in order to compare the effects of each dose of caffeine on HRV before and 60 minutes after drinking the energy drinks and after the exercise. The subjects were told not to move or talk during the measurement. Based on the limb leads, electrodes were placed at three locations: left arm, left leg and right leg.

\section{Data analysis}

Data from this study were analyzed by SPSS/pc 20.0 Statistics for Windows in order to calculate mean deviation and standard deviation of each variable. Homogeneity test was conducted on subjects of each group to make sure their physical characteristics and exercise performance ability were similar to each other. Also, one-way ANOVA was conducted to identify different exercise time between the groups. Twoway repeated measure ANOVA was conducted to identify different heart rate, RPE, respiratory variables checked at each measurement time. The two-way repeated measure ANOVA was also used to identify difference between heart rate and HRV checked before and after the exercise. When differences were found in main effect, one-way ANOVA was used to analyze differences between each group at each measurement time. When significant differences were found between measurement times, Tukey post hoc was used to follow-up with the group factor. $a=0.05$ was classified to have statistical significance.

\section{RESULTS}

\section{Difference of exercise performance ability between groups}

Difference of exercise time between groups

Results from the one-way ANOVA showed a significant increase of exercise time in ECGII than the control group

Table 2. The difference of exercise time between groups

\begin{tabular}{lc}
\hline \multicolumn{1}{c}{ Group } & Exercise time (s) \\
\hline CON (a) & $474.80 \pm 72.31$ \\
ECG I (b) & $608.20 \pm 118.97$ \\
ECG II (c) & $672.40 \pm 141.05$ \\
\hline $\mathrm{F}$ & 3.880 \\
$\mathrm{p}$ & .05 \\
post hoc & $\mathrm{a}<\mathrm{c}$ \\
\hline Values are Mean \pm Standard deviation & \\
CON : control group, ECG I : energy drink $1.25 \mathrm{mg} / \mathrm{kg}^{-1}$ consumption group, \\
ECG II: energy drink $2.5 \mathrm{mg} / \mathrm{kg}^{-1}$ consumption group
\end{tabular}


Table 3. The difference of heart rate between groups during exercise

(unit : beat $/ \mathrm{min}$ )

\begin{tabular}{lcccccccc}
\hline \multirow{2}{*}{ Group } & \multirow{2}{*}{ Rest } & \multicolumn{7}{c}{ During exercise } \\
\cline { 3 - 7 } & & $1 \mathrm{~min}$ & $2 \mathrm{~min}$ & $3 \min$ & $4 \min$ & $5 \min$ & $6 \min$ \\
\hline CON & $59.80 \pm 7.70$ & $157.00 \pm 6.78$ & $169.80 \pm 9.12$ & $173.60 \pm 10.67$ & $179.20 \pm 10.43$ & $183.20 \pm 10.57$ & $184.00 \pm 13.84$ & $190.00 \pm 10.79$ \\
ECG I & $57.00 \pm 6.96$ & $158.80 \pm 9.28$ & $168.40 \pm 4.16$ & $169.60 \pm 8.47$ & $176.20 \pm 2.17$ & $177.60 \pm 5.41$ & $180.40 \pm 4.16$ & $186.00 \pm 5.39$ \\
ECG II & $61.00 \pm 2.92$ & $159.20 \pm 11.32$ & $172.40 \pm 9.91$ & $178.40 \pm 7.60$ & $182.40 \pm 6.23$ & $187.00 \pm 6.12$ & $186.20 \pm 10.62$ & $194.20 \pm 7.26$ \\
\hline
\end{tabular}

Values are Mean \pm Standard deviation

CON : control group, ECG I : energy drink $1.25 \mathrm{mg} / \mathrm{kg}^{-1}$ consumption group, ECG II: energy drink $2.5 \mathrm{mg} / \mathrm{kg}^{-1}$ consumption group

Table 4. The difference of RPE between groups during exercise

\begin{tabular}{lcccccc}
\hline \multirow{2}{*}{ Group } & \multicolumn{6}{c}{ During exercise } \\
\cline { 2 - 7 } & $1 \mathrm{~min}$ & $2 \mathrm{~min}$ & $3 \mathrm{~min}$ & $4 \mathrm{~min}$ & $5 \mathrm{~min}$ & $6 \mathrm{~min}$ \\
\hline CON & $11.20 \pm 1.10$ & $12.60 \pm 0.89$ & $14.60 \pm 1.67$ & $15.40 \pm 1.67$ & $16.60 \pm 2.19$ & $17.00 \pm 2.00$ \\
ECG I & $12.20 \pm 1.10$ & $13.80 \pm 1.10$ & $14.20 \pm 1.10$ & $15.40 \pm 1.67$ & $16.20 \pm 1.10$ & $16.20 \pm 1.10$ \\
ECG II & $11.80 \pm 1.10$ & $12.60 \pm 1.67$ & $14.00 \pm 2.00$ & $14.80 \pm 1.10$ & $15.20 \pm 1.48$ & $15.40 \pm 1.52$ \\
\hline
\end{tabular}

Values are Mean \pm Standard deviation

CON : control group, ECG I : energy drink $1.25 \mathrm{mg} / \mathrm{kg}^{-1}$ consumption group, ECG II : energy drink $2.5 \mathrm{mg} / \mathrm{kg}^{-1}$ consumption group

Table 5. The difference of respiration variables between groups during exercise

\begin{tabular}{|c|c|c|c|c|c|c|c|c|}
\hline & \multirow{2}{*}{ Group } & \multicolumn{6}{|c|}{ During exercise } & \multirow{2}{*}{ Max } \\
\hline & & $1 \mathrm{~min}$ & $2 \mathrm{~min}$ & $3 \min$ & $4 \mathrm{~min}$ & $5 \mathrm{~min}$ & $6 \mathrm{~min}$ & \\
\hline \multirow{3}{*}{$\begin{array}{l}\mathrm{VO}_{2} \\
(\mathrm{~mL} / \mathrm{kg} / \mathrm{min})\end{array}$} & $\mathrm{CON}$ & $20.34 \pm 3.89$ & $31.06 \pm 4.38$ & $47.24 \pm 5.98$ & $50.50 \pm 5.96$ & $53.28 \pm 6.65$ & $54.72 \pm 6.38$ & $56.18 \pm 5.68$ \\
\hline & ECG I & $23.32 \pm 3.80$ & $30.72 \pm 3.53$ & $45.58 \pm 2.65$ & $50.48 \pm 3.78$ & $54.34 \pm 2.35$ & $54.78 \pm 4.12$ & $60.78 \pm 7.45$ \\
\hline & ECG ॥ & $20.08 \pm 2.13$ & $30.88 \pm 2.50$ & $45.24 \pm 3.24$ & $46.26 \pm 16.84$ & $54.48 \pm 3.12$ & $55.96 \pm 4.74$ & $62.92 \pm 7.17$ \\
\hline \multirow{3}{*}{$\begin{array}{l}\mathrm{VE} \\
(\mathrm{L} / \mathrm{min})\end{array}$} & $\mathrm{CON}$ & $32.81 \pm 5.05$ & $45.97 \pm 7.78$ & $78.73 \pm 14.65$ & $98.01 \pm 13.37$ & $107.02 \pm 16.27$ & $112.68 \pm 18.58$ & $125.93 \pm 16.77$ \\
\hline & ECG I & $40.66 \pm 5.65$ & $52.29 \pm 9.04$ & $74.54 \pm 9.68$ & $92.64 \pm 7.60$ & $103.14 \pm 10.17$ & $105.94 \pm 10.60$ & $131.69 \pm 13.57$ \\
\hline & ECG II & $38.89 \pm 9.13$ & $50.76 \pm 7.20$ & $77.60 \pm 9.63$ & $95.25 \pm 12.65$ & $98.64 \pm 11.69$ & $113.21 \pm 12.96$ & $131.33 \pm 10.75$ \\
\hline \multirow{3}{*}{$\begin{array}{l}\text { VT } \\
\text { (L) }\end{array}$} & $\mathrm{CON}$ & $1.68 \pm 0.45$ & $2.20 \pm 0.38$ & $2.97 \pm 0.80$ & $3.14 \pm 0.70$ & $3.18 \pm 0.52$ & $3.08 \pm 0.40$ & $3.21 \pm 0.47$ \\
\hline & ECG I & $1.71 \pm 0.38$ & $2.20 \pm 0.40$ & $2.87 \pm 0.62$ & $3.22 \pm 0.66$ & $3.44 \pm 0.72$ & $3.24 \pm 0.62$ & $3.54 \pm 0.75$ \\
\hline & ECG ॥ & $1.63 \pm 0.54$ & $2.09 \pm 0.68$ & $3.07 \pm 0.85$ & $3.42 \pm 0.72$ & $3.34 \pm 0.72$ & $3.29 \pm 0.65$ & $3.42 \pm 0.65$ \\
\hline \multirow{3}{*}{$\begin{array}{l}\mathrm{RR} \\
\text { (beat/min) }\end{array}$} & $\mathrm{CON}$ & $20.20 \pm 3.27$ & $21.00 \pm 2.35$ & $27.40 \pm 5.86$ & $32.20 \pm 6.61$ & $34.20 \pm 6.30$ & $36.80 \pm 4.87$ & $40.80 \pm 5.72$ \\
\hline & ECG I & $24.20 \pm 4.44$ & $24.20 \pm 4.09$ & $26.60 \pm 4.45$ & $29.60 \pm 5.51$ & $30.80 \pm 6.18$ & $33.40 \pm 6.35$ & $43.60 \pm 8.85$ \\
\hline & ECG ॥ & $26.80 \pm 13.50$ & $27.00 \pm 11.90$ & $27.80 \pm 11.95$ & $29.40 \pm 10.21$ & $31.00 \pm 9.46$ & $35.80 \pm 9.07$ & $43.00 \pm 3.00$ \\
\hline
\end{tabular}

Values are Mean \pm Standard deviation

CON : control group, ECG I : energy drink $1.25 \mathrm{mg} / \mathrm{kg}^{-1}$ consumption group, ECG II: energy drink $2.5 \mathrm{mg} / \mathrm{kg}^{-1}$ consumption group

as shown in the $<$ Table $2>(\mathrm{p}=0.05)$.

Difference of heart rate between groups during exercise

The two-way repeated measure ANOVA was conducted to find out the difference of heart rate between groups and measurement time. It showed a significant difference between measurement times $(p<0.001)$, but not between groups ( $p$ $>0.05)$. No interaction between groups and measurement times was found either $(p>0.05)$. Difference of respiratory variables between groups is shown in the $\langle$ Table $3>$.

The difference of RPE between groups during exercise

The two-way repeated measure ANOVA was conducted to find out the difference of RPE between groups and measure- ment time. It showed a significant difference between measurement times $(p<0.001)$, but not between groups $(p>$ $0.05)$. No interaction between groups and measurement times was shown either $(p>0.05)$. Difference of RPE between groups is shown in the $<$ Table $4>$.

The difference of respiration variables between groups during exercise

The two-way repeated measure ANOVA was conducted to find out the difference of respiration variables between groups and measurement time. It showed a significant difference between measurement times $(\mathrm{p}<0.001)$, but not between groups $(p>0.05)$. No interaction between groups and measurement times was shown either $(p>0.05)$. Difference of respiration 
Table 6. The difference of heart rate recovery between groups

(unit : beat $/ \mathrm{min}$ )

\begin{tabular}{ccccccc}
\hline Group & Before intake & 60min after intake & Max & 1 min after exercise & 2 min after exercise 3 min after exercise \\
\hline CON & $59.80 \pm 7.70$ & $64.40 \pm 6.35$ & $190.00 \pm 10.79$ & $164.20 \pm 5.93$ & $118.40 \pm 7.13$ & $105.40 \pm 7.02$ \\
ECG I & $57.00 \pm 6.96$ & $59.40 \pm 7.60$ & $186.00 \pm 5.39$ & $159.00 \pm 3.32$ & $123.20 \pm 5.36$ & $103.60 \pm 5.27$ \\
ECG II & $61.00 \pm 2.92$ & $64.40 \pm 3.65$ & $194.20 \pm 7.26$ & $167.80 \pm 5.59$ & $127.00 \pm 11.05$ & $109.00 \pm 8.37$ \\
\hline
\end{tabular}

Values are Mean \pm Standard deviation

CON : control group, ECG I : energy drink $1.25 \mathrm{mg} / \mathrm{kg}^{-1}$ consumption group, ECG Il : energy drink $2.5 \mathrm{mg} / \mathrm{kg}^{-1}$ consumption group

Table 7. The difference of Blood pressure between groups

(unit : mmHg)

\begin{tabular}{lcccccc}
\hline \multirow{2}{*}{ Group } & \multicolumn{2}{c}{ Before intake } & \multicolumn{2}{c}{$60 \mathrm{~min}$ after intake } & \multicolumn{2}{c}{ After exercise } \\
\cline { 2 - 7 } & SBP & DBP & SBP & DBP & SBP & DBP \\
\hline CON & $111.20 \pm 4.66$ & $67.80 \pm 9.71$ & $112.80 \pm 7.12$ & $65.80 \pm 6.94$ & $136.40 \pm 8.14$ & $65.80 \pm 7.33$ \\
ECG I & $122.00 \pm 10.79$ & $71.00 \pm 13.00$ & $126.40 \pm 9.97$ & $66.40 \pm 11.04$ & $149.20 \pm 24.75$ & $65.00 \pm 7.58$ \\
ECG II & $121.40 \pm 9.02$ & $72.60 \pm 5.86$ & $120.60 \pm 10.41$ & $69.00 \pm 7.58$ & $153.40 \pm 16.23$ & $69.60 \pm 7.37$ \\
\hline
\end{tabular}

Values are Mean \pm Standard deviation

CON : control group, ECG I : energy drink $1.25 \mathrm{mg} / \mathrm{kg}^{-1}$ consumption group, ECG II: energy drink $2.5 \mathrm{mg} / \mathrm{kg}^{-1}$ consumption group

Table 8. The difference of heart rate variability between groups

\begin{tabular}{|c|c|c|c|c|}
\hline \multirow{2}{*}{ HRV } & \multirow{2}{*}{ Group } & \multicolumn{3}{|c|}{ Result } \\
\hline & & Before intake & After intake & After exercise \\
\hline \multirow{3}{*}{$\begin{array}{l}\text { SDNN } \\
\text { (ms) }\end{array}$} & $\mathrm{CON}$ & $68.52 \pm 26.77$ & $70.79 \pm 33.58$ & $14.27 \pm 4.96$ \\
\hline & ECG I & $62.71 \pm 20.84$ & $54.00 \pm 17.51$ & $11.70 \pm 3.53$ \\
\hline & ECG II & $43.20 \pm 12.72$ & $63.15 \pm 20.10$ & $10.04 \pm 4.19$ \\
\hline \multirow{3}{*}{$\begin{array}{l}\text { RMSSD } \\
\text { (ms) }\end{array}$} & $\mathrm{CON}$ & $62.06 \pm 37.65$ & $53.19 \pm 22.68$ & $4.90 \pm 2.07$ \\
\hline & ECG I & $61.27 \pm 20.71$ & $58.60 \pm 22.71$ & $4.23 \pm 0.85$ \\
\hline & ECG II & $31.61 \pm 13.97$ & $46.61 \pm 19.29$ & $4.00 \pm 1.03$ \\
\hline \multirow{3}{*}{$\begin{array}{l}\text { TP } \\
(\mathrm{ms} 2)\end{array}$} & $\mathrm{CON}$ & $8.01 \pm 0.97$ & $8.28 \pm 10.5$ & $4.46 \pm 0.98$ \\
\hline & ECG I & $8.05 \pm 0.78$ & $7.56 \pm 0.52$ & $4.00 \pm 0.41$ \\
\hline & ECG II & $6.83 \pm 1.00$ & $7.93 \pm 0.85$ & $3.55 \pm 0.42$ \\
\hline \multirow{3}{*}{$\begin{array}{l}\text { VLF } \\
(\mathrm{ms} 2)\end{array}$} & CON & $7.18 \pm 0.81$ & $7.27 \pm 0.68$ & $4.03 \pm 0.91$ \\
\hline & ECG I & $7.28 \pm 1.04$ & $6.28 \pm 1.33$ & $3.58 \pm 0.48$ \\
\hline & ECG II & $5.76 \pm 0.89$ & $7.17 \pm 1.43$ & $3.26 \pm 0.67$ \\
\hline \multirow{3}{*}{$\begin{array}{l}\text { LF } \\
\text { (ms2) }\end{array}$} & $\mathrm{CON}$ & $6.43 \pm 0.98$ & $7.43 \pm 1.42$ & $3.08 \pm 1.37$ \\
\hline & ECG I & $6.65 \pm 0.59$ & $6.20 \pm 0.23$ & $2.53 \pm 0.52$ \\
\hline & ECG II & $5.62 \pm 1.29$ & $6.09 \pm 0.79$ & $1.89 \pm 0.65$ \\
\hline \multirow{3}{*}{$\begin{array}{l}\mathrm{HF} \\
(\mathrm{ms} 2)\end{array}$} & $\mathrm{CON}$ & $6.67 \pm 6.44$ & $6.16 \pm 0.74$ & $1.47 \pm 0.66$ \\
\hline & ECG I & $6.44 \pm 1.10$ & $6.27 \pm 0.78$ & $1.04 \pm 0.56$ \\
\hline & ECG II & $5.35 \pm 1.24$ & $6.23 \pm 0.80$ & $0.68 \pm 0.47$ \\
\hline \multirow{3}{*}{ LF Norm } & $\mathrm{CON}$ & $46.00 \pm 25.29$ & $74.73 \pm 14.48$ & $84.92 \pm 9.49$ \\
\hline & ECG I & $54.29 \pm 21.62$ & $48.21 \pm 21.96$ & $84.27 \pm 8.01$ \\
\hline & ECG II & $56.26 \pm 19.09$ & $47.86 \pm 23.34$ & $78.49 \pm 8.27$ \\
\hline \multirow{3}{*}{ HF Norm } & $\mathrm{CON}$ & $25.23 \pm 11.28$ & $25.27 \pm 14.48$ & $15.08 \pm 9.50$ \\
\hline & ECG I & $45.71 \pm 21.62$ & $51.79 \pm 22.00$ & $15.73 \pm 8.01$ \\
\hline & ECG II & $43.74 \pm 19.09$ & $52.14 \pm 23.34$ & $21.51 \pm 8.27$ \\
\hline \multirow{3}{*}{$\mathrm{LF} / \mathrm{HF}$ ratio } & $\mathrm{CON}$ & $1.26 \pm 1.16$ & $2.61 \pm 1.13$ & $5.40 \pm 4.38$ \\
\hline & ECG I & $1.76 \pm 1.60$ & $1.32 \pm 1.22$ & $4.36 \pm 1.79$ \\
\hline & ECG॥ & $1.68 \pm 1.17$ & $1.25 \pm 0.96$ & $4.40 \pm 2.47$ \\
\hline
\end{tabular}

Values are Mean \pm Standard deviation

CON : control group, ECG I : energy drink $1.25 \mathrm{mg} / \mathrm{kg}^{-1}$ consumption group,

ECG II : energy drink $2.5 \mathrm{mg} / \mathrm{kg}^{-1}$ consumption group variables between groups is shown in the $<$ Table $5>$.

\section{Difference of variables between groups before and after exercise}

\section{Difference of heart rate recovery between groups}

The two-way repeated measure ANOVA was conducted to find out the difference of heart rate between groups and measurement times. It showed a significant difference between measurement times $(p<0.001)$, but not between groups $(p>0.05)$. No interaction between groups and measurement times was shown either $(p>0.05)$. Difference of heart rate between groups before and after exercise is shown in the $<$ Table $6>$.

\section{The difference of blood pressure between groups}

The two-way repeated measure ANOVA was conducted to find out the difference of blood pressure between groups and measurement times. It showed a significant difference between measurement times $(\mathrm{p}<0.001)$, but not between groups $(\mathrm{p}$ $>0.05$ ). No interaction between groups and measurement times was shown either $(p>0.05)$. Difference of blood pressure between groups before and after exercise is shown in the $<$ Table $7>$.

The difference of heart rate variability between groups

The two-way repeated measure ANOVA was conducted to find out the difference HRV between groups and measurement times. It showed a significant difference between measurement times $(p<0.001)$, but not between groups $(p>0.05)$. No interaction between groups and measurement times was shown either $(\mathrm{p}>0.05)$. Difference of HRV between groups before and after exercise is shown in the $\langle$ Table $8>$. 


\section{DISCUSSION}

Energy drinks are drawing attention nowadays not only among athletes but also among ordinary people as supplemental health food. They are known to improve mental and physical strength. They are popular especially among those in their teens and 20s. Caffeine is known to be consumed by athletes for its ergogenic effect and other effects to improve alertness and cognitive performance [18]. However, side effects [19] triggered by too much caffeine consumption and long-term consumption increased concerns over consumers' health and safety. Thus, this study intends to provide accurate information about energy drinks and also to provide meaningful information about the effects of caffeine dose in energy drinks as a health supplement to enhance exercise performance ability within a safe caffeine limit that would not cause any negative caffeine overdose symptoms.

Exercise time, heart rate, rating of perceived exertion (RPE), and respiratory variable were monitored in order to identify difference of exercise performance ability between groups. ECG II showed a statistically significant increase in exercise time than control group $(p=0.05)$. In similar studies such as Alford dt al. [20], 38 subjects who had drunken Red Bull (80mg of caffeine) 30 minutes before they ran cycles at $65 \sim 75 \%$ of their maximal heart rate showed a significant increase in exercise time than the placebo group $(\mathrm{p}<0.05)$. However, in a study by Darren et al. [16], subjects who had drunken sugar-free Red Bull $\left(2 \mathrm{mg} / \mathrm{kg}^{-1}\right)$ one hour before they ran at $80 \%$ of their maximum oxygen consumption showed no significant changes in RPE, blood lactate, and exercise time.

In another study by Gregory et al. [21], subjects who had drunken soft drink (cola) that contained caffeine $\left(1.9 \mathrm{mg} / \mathrm{kg}^{-1}\right)$ and carbohydrates before they ran cycles showed 3.3\% increase in exercise ability than the placebo group. The study reported that the results indicated that low dose of caffeine requires carbohydrate if it is to produce ergogenic effect. Thus, statistically significant increase of exercise time with low dose of caffeine intake $(p=0.05)$ from this study indicate the fact that the concentration of caffeine positively affects exercise time when other ingredients are the same.

Heart rate refers to the number of heartbeats per unit of. It is considered an important index that indicates physiological responses of heart function. It is also a good index that shows intensity of stress as body's need to absorb oxygen goes up with the intensity of exercise [22]. The results from this study showed no statistically significant differences in maximal heart rate, heart rate at rest and exercise between control group, ECG I and, ECG II ( $p>0.05)$. Likewise, a study by
Gregory et al. [21] that had its subjects run cycles showed no significant differences in heart rate between a group that consumed drinks with carbohydrate and caffeine and a placebo group $(\mathrm{p}>0.05)$. A study by Janae et al. [23] also showed no significant difference in heart rate in those who consumed low dose caffeine, indicating that low dose of caffeine consumption does not affect heart rate. Therefore, we concluded that consumption of energy drinks with recommended safe caffeine intake limit does not affect maximal heart rate, heart rate at rest and exercise as shown in the results from this study.

RPE of each group also showed no statistically significant difference $(\mathrm{p}>0.05)$. Studies that reported opposite results to this study include Bruce et al. [24] that said intake of 3-9 $\mathrm{mg} / \mathrm{kg}^{-1}$ caffeine resulted in decreased fatigue. A study by Allyson et al. [25] also reported statistically significant decrease in RPE in a group that drank energy drinks and ran treadmill at $70 \%$ of their maximal oxygen consumption when their RPE was compared to that of placebo group. Therefore, we concluded that consumption of energy drinks with recommended safe caffeine limit does not affect RPE as shown in the results from this study.

Respiratory variables are one of physiological variables related to metabolic mechanism during exercise. It can be used as an important analysis index for many changes associated with the usage of oxygen. Also response of respiratory variables is one of major physiological changes that define limit of exercise. Maximal oxygen consumption reflects the maximal ability of the body to deliver oxygen to muscles to eliminate waste matters produced by long -term exercise. It also reflects the aerobic physical fitness of the individual, and is an important determinant of their endurance capacity during prolonged, sub-maximal exercise [27]. The results from this study showed no statistically significant differences in respiratory variables between the groups $(p>0.05)$. In a study by Janae et al. [23] that had its subjects drink three kinds of energy drinks and run treadmills at $50 \%$ of their maximal oxygen consumption 30 minutes after the intake, no statistically significant difference in oxygen consumption were seen $(\mathrm{p}$ $>0.05$ ) due to low intensity of exercise and intake of low dose caffeine. Therefore, we concluded that consumption of energy drinks with recommended safe caffeine limit does not affect respiratory variables as shown in the results from this study. While heart rate, RPE, respiratory variables were not significantly different in groups that drank energy drinks, significant difference was found in exercise time in control group and ECG $I(p=0.05)$. Therefore, we concluded from the results that intake of energy drinks with $2.5 \mathrm{mg} / \mathrm{kg}^{-1}$ caffeine has positive effect on physical performance during 
high intensity exercise.

Heart rate recovery, blood pressure and HRV of each group were measured before and after the exercise in order to identify difference of variables between groups before and after exercise. Heart rate measured before and 60 minutes after the intake showed no statistically significant differences between the groups $(\mathrm{p}>0.05)$. In a study by Janae et al. [23], no statistically significant difference in heart rate at rest $(60$ minutes after the intake) was seen $(p>0.05)$. Also, in a study by Frances et al. [2] that had its subjects drink low calorie Red Bull and normal calorie Red Bull, no statistically significant difference in heart rate was seen in groups that drank energy drinks compared to the placebo group $(p>0.05)$. The study also reported that intake of energy drinks with more than $3 \mathrm{mg} / \mathrm{kg}^{-1}$ caffeine resulted in increased heart rate, while intake of energy drinks with low dose caffeine (less than 2 $\mathrm{mg} / \mathrm{kg}^{-1}$ ) produced no difference in heart rate at rest. Therefore, we concluded that intake of low dose caffeine produces no particular difference in heart rate at rest.

Heart rate recovery after exercise cessation is thought to reflect the rate of reestablishment of physical function. Cessation of exercise leads to drop in heart rate because it reestablishes parasympathetic tone, decreasing cardiac output [28]. Heart rate recovery varies by individual but athletes or those who exercise regularly are proven to recover faster than others. Physically strong people have been reported to recover faster after exercise than those who are not. In this study, we've measured recovery heart rate of individuals after exercise in order to study parasympathetic nerve activity. However, no statistically significant differences were found between the groups $(\mathrm{p}>0.05)$. In a study by Imai et al. [29] that measured recovery heart rate of healthy adults, athletes and chronic heart failure patients, heart rate of athletes decreased fast in 30 seconds after exercise test, while patients with chronic heart failure showed little decrease in heart rate. Also, in a study by Cole et al. [30] suggested that recovery heart rate reflected parasympathetic activity and that slow recovery indicated lack of vegal reactivation and that impaired heart rate recovery predicted higher mortality in patients with cardiovascular disease.

Thus, no difference between groups seen from the results of this study indicates that intake of energy drinks with 2.5 $\mathrm{mg} / \mathrm{kg}^{-1}$ caffeine produces no cardiovascular side effects during short-term high intensity exercise. Intake of caffeine reportedly prompts secretion of norepinephrine and epinephrine to increase force of the muscle's contraction, raising the rate and force of the heart, thereby increasing the blood pressure and make the heart beat faster [9]. However, in this study, no statistically significant difference in blood pressure was seen between groups $(p>0.05)$ probably because intake of low dose caffeine did not affect blood pressure as did with heart rate. In a study by Assmann et al. [31], those with high systolic blood pressure and low diastolic blood pressure were suggested to be at highest risk for cardiovascular disease. Thus, no difference between groups seen from the results of this study indicates that intake of energy drinks with 2.5 $\mathrm{mg} / \mathrm{kg}^{-1}$ caffeine produces no cardiovascular side effects during short-term high intensity exercise.

Heart rate variability (HRV) reflects the simultaneous affect of the sympathetic and parasympathetic nervous system of autonomic nervous system on the heart, which results in a beat-to-beat variability on an electrocardiographic (ECG) rhythm strip. HRV is widely used as a noninvasive measure [32]. During exercise, HRV gets decreased due to an increase of sympathetic activity and decrease in parasympathetic activity. It reflects an increase of heart rate, stroke volume and myocardial contractility [33]. Fast heart rate recovery after exercise restores HRV toward normal level due to reactivation of parasympathetic nervous system [29]. A study by Cole et al. [30] reported that lack of vegal response after exercise indicate high risk of death from cardiovascular disease due to impaired reduction in HRR. Thus, parasympathetic nervous activity after exercise is considered an important index that reflects effects of energy drink intake on cardiovascular system. In this study, HRV was measured to study effects of energy drinks on autonomic nervous system before and 60 minutes after the intake and parasympathetic nervous system activity in the control group and intervention groups after the exercise. Unlike results from previous studies, results from this study showed no statistically significant difference between groups $(p>0.05)$ probably because low dose caffeine was used for the study. However, in a study by Urban et al. [34] which had its subjects drink three cans of energy drinks, statistically significant decrease was shown in TP, LF, HF and LF/HF after exercise $(p<0.05)$. The study reported that intake of energy drinks may cause risk for arrhythmia because intake of energy drinks interrupts parasympathetic nervous system activity, affecting autonomic nervous system control of heart rate [35]. However, use of caffeine dose within a safe limit in this study produced different results. In this study, ECGII that drank $2.5 \mathrm{mg} / \mathrm{kg}^{-1}$ caffeine showed a statistically significant increase in exercise time than control group but showed no significant difference in HRV after exercise.

In conclusion, intake of energy drinks with $2.5 \mathrm{mg} / \mathrm{kg}^{-1}$ caffeine which is within the safe caffeine limit produced no significant changes in heart rate, blood pressure and HRV before and after exercise. However, it did have positive effects 
on exercise performance ability and did not cause side effects in cardiovascular system after exercise.

\section{ACKNOWLEDGEMENTS}

The research was supported by a Korea University Grant.

\section{REFERENCES}

[1] Embrain Trend Monitor. 2012 U\&A Report on Energy Drinks

[2] Frances RR, Tyler DG, Narjes B, Nicole H, April M, Erin CM, Thomas W, Nalli CM, Mannello CJ, Sell PJ, McCann GM, Kastello TH, Ted W. Effect of red bull energy drink on cardiovascular and renal function Amino Acids $2010 ; 38$ : 1193-1200.

[3] Scott CF, Darren GC, Jonathan PL, Charlene M, Philip DC. Effect of Red Bull Energy Drink on Repeated Wingate Cycle Performance and Bench-Press Muscle Endurance. Int Jour of Sport Nutrition and Metab 2007; 17:433-444.

[4] James M. The potential adverse health effects of energy drinks Am Fam Physician 2013;87(5):321.

[5] Leda muaoz CL, Keen B, Kathryn GD. Coffee intake during pregnancy and lactation in rats: maternal and pup hematological parameters and liver iron, zinc and copper concentration J. Nutr 1986;116(7):1326-1333.

[6] Ryoo Seung-pil, Seo Il-ho, Lee Soo-cheon. Effects of caffeine ingestion on muscle power output in trained and untrained adolescents. Korean Journal of Exercise Nutrition 2002;6(1):1-10.

[7] Melanie AH, Jorge W, Elvira GM. Caffeine (1, 3, 7-trimethylxanthine) in foods: a comprehensive review on consumption, functionality, safety, and regulatory matters J Food Sci 2010;75(3):77-87.

[8] Ministry of Food \& Drug Safety (2011). Contents of caffeine in food and labeling standard

[9] Lee Hye-won. A Study on Caffeine containing foods and the effect of caffeine in humans. Korean Journal of Culinary Research 2000;6(3):343-355.

[10] Arne A, Sren T, Stephen C, Pia H, Lezf B, Joop M. Caffeine: a double-blind, placebo-controlled study of its thermogenic, metabolic and cardiovascular effects in healthy volunteers Am J Clin Nutr 1990;51(5):759-767.

[11] Jo Hong-gwan, Lee Cheol-won. Effects of caffeine intake on changes of blood energy substrate of longdistance runners. Korean Journal of Exercise Nutrition
1998;2(1):45-56

[12] Costill DL, Coyle E, Dalshy W, Evans W, Fink D, Hoopes D. Effects of elevated plasma FFA and insulin on muscle glycogen usage during exercise Journal of Applied Physiology 1997;45(4):695-599.

[13] Goldstein E, Ziegenfuss T, Kalman D, Kreider R, Campbell B, Wilborn C, Taylor L, Antonio J. caffeine \& performance. Journal of the international society of sports nutrition 2010;7(5):1-15.

[14] Roberson R, Astorino T. Recommendations for improved data processing from expired gas analysis indirect calorimetry Sports Medicine 2010;40(2):95-111.

[15] Reissig CJ, Strain EC, Griffiths RR.. Caffeinated energy drinks a growing problem Drug Alcohol Depend 2009; 99(1):1-10.

[16] Darren GC, Amanda KK, Stephanie G, Kim DD. Effect of sugar $=$ free red bull energy drink on high-intensity run time to exhaustion in young adults journal of strength and conditioning research 2009;23(4):1271-1275.

[17] Graham TE, Spriet LL. Metabolic, catecholamine, and exercise performance responses to various doses of caffeine J Appl Physiol 1995;78(3):867-874.

[18] Kim Tae-wook, Park Bong-seop. Effects of 3mg,kg(-1) Caffeine Ingestion during Exercise on Fluid-Electrolyte Balance and Tympanic temperature changes in the Heat. Korean Journal of Exercise Nutrition 2009;13(1):75-81.

[19] Jo Hong-gwan, Lee Cheol-won. Effects of caffeine intake on changes of blood energy substrate of long-distance runners. Korean Journal of Exercise Nutrition 1998;2(1): 45-56

[20] Alford C, Cox H, R. W. The effects of red bull energy drink on human performance and mood Amino acids 2001;21(2):139-150

[21] Gregory R, Ben D, Paul G, Megan E, Clinton R, Theodore A, David T, Angela, M, Alan R, John A, Louise M. Effect of different protocols of caffeine intake on metabolism and endurance performance Journal of Applied physiology 2002;93(3):990-999.

[22] Asmunseen E, Nielsen M. The cardiac output in rest and work at low and high oxygen pressures Acta Physiologica Scandinavica, 1955;35(1):73-83.

[23] Janae N, Gregory AB, Brandon SS, Ina S. Effects of energy on metabolism at rest and during submaximal treadmill exercise in college age males Int J Exer Sci 2011;22(3):65-75.

[24] Bruce C, Anderson M, Fraser S. Enhancement of 2000-m rowing performance after caffeine ingestion Med. Sci. Sports Exerc, 2000;33:1399-1403.

[25] Allyson L., Adam M., Nicholas A., Jie K., \& Jay R. 
Improved time to exhaustion following ingestion of the energy drink amino impact Journal of the international society of sports nutrition 2010;7-14.

[26] Ahn Sang-min, Park Jong-seok, Kim Sang-ho. The Effects of Nicotine Patch on Exercise Capacity and Cardiovascular Reaction during Graded Exercise in Smokers. Journal Korean Society for the Study of Physical Education 2013;18(2):261-274.

[27] Kim Gi-jin, Bae Ji-hyun. Effects of Sports Drink Including the Extract from Prunus mume on the Changes of Respiratory Variables, Heart Rate, and Blood Lactate Concentration in Submaximal Exercise. Journal of the East Asian Society of Dietary Life 1999;9(2):177-187.

[28] Scott K. Powers. Exercise physiology: theory and applications to fitness and performance 2008 .

[29] Imai K, Nakachi. Cross sectional study of effects of drinking green tea on cardiovascular and liver diseases BMJ 1995;310(6981):693-696.

[30] Cole CR, Eugene, HB, Fredric JP, Claire, ES, Lauer MS. Heart rate recovery immediately after exercise as a predictor of mortality N Engl J Med 1999;341:1351-
1357.

[31] Assmann G, Cullen P, Evers T, Petzinna D, Schulte H. Importance of arterial pulse pressure as a predictor of coronary heart disease risk in PROCAM Eur heart $\mathrm{J}$ 2003;26(20):2120-2126.

[32] Lee Soo-gyeong, Kim Eun-gyeong, Kim Sang-ho. The Effect of Treadmill Exercise in Water on Autonomic Nervous System. Journal of Sports and Leisure Studies 2005;25:393-406.

[33] Javorka M, Zila I, Balharek T, Javorka K. On and off responses of heart rate to exercise : relations to heart rate variability. Clim physiol Funct Imaging 2003;23:1-8.

[34] Urban, W., Marcus, K., Mats, O., \& Torbjorn, M. Influence of energy drinks and alcohol on post-exercise heart rate recovery and heart rate variability Clin Physiol Funct Imaging 2009;29(1):74-80.

[35] Ewing, D., Neilson, J., Shapiro, C., Steward, T. \& Reid, W. Effects of posture, sleep and time of day in healthy controls and comparison with bedside tests of autonomic function in diabetic patients Br Heart J 1991;65:239-244. 